\title{
Strengths, Weaknesses, Opportunities and Threats (SWOT) of A Holistic Extension Programme: Case Study of Farm Attachment Programme in Kenya
}

\author{
Benjamin W. Kisiangani ${ }^{1} \quad$ Oscar I. Ayuya $^{1} \quad$ Nancy W. Mungai ${ }^{2}$ \\ 1.Department of Agricultural Economics and Agribusiness Management, Egerton University, Kenya \\ 2.Department of Crops, Horticulture and Soils, Egerton University, Kenya
}

\begin{abstract}
This paper examines the perceptions of farmers towards a student-farmer centered extension arrangement called the Farm Attachment Programme (FAP). Despite the pertinence of Agriculture to the economy, its potential has not been realized. To address this shortfall, research and training institutions have designed and generated knowledge and technologies. However, the innovations generated have hardly reached the end users. In response, Egerton University established Farm Attachment Programme (FAP) to innovatively engage smallscale farmers in 2014. As a result, the study sought to determine the Strengths, Weaknesses, Opportunities and Threats (SWOTs) of the farm attachment program. A census survey of 100 farmers that had been engaged in FAP in Nakuru and Baringo Counties in Kenya was conducted using semi - structured questionnaires. The study employed a Confirmatory Factor Analysis(CFA) model to examine how the farmers felt about the programme in terms of Strengths, Weaknesses, Opportunities and Threats. From the SWOT analysis, higher factor loadings of 0.763 on Factor 2 indicated that increased technology awareness and access among farmers was the main strength of FAP while 0.686 on Factor 1 indicated that increase in farmer linkage was the main opportunity. On the other hand, loadings of 0.830 and 0.760 on factor 3 and 4 indicated that short attachment duration and high costs of student accommodation were the main weakness and threat of FAP respectively. The study recommends for a review of the attachment duration to at least twelve or more weeks to ensure successful implementation of the interventions introduced by the students. Based on the strengths and opportunities presented by the FAP, the study further recommends that the programme should be expanded to other counties.
\end{abstract}

Keywords: Farm attachment programme: Agricultural productivity: SWOT analysis: Confirmatory Factor Analysis.

DOI: $10.7176 / \mathrm{JEP} / 10-30-12$

Publication date:October $31^{\text {st }} 2019$

\subsection{Introduction}

The economic development in Kenya heavily depends on agriculture which accounts for $75 \%$ of the labour force, approximately $45 \%$ of the Gross Domestic Product (GDP), and over 60\% of the total exports (KNBS, 2018). Therefore, agricultural development has been targeted as one of the primal pathways to poverty reduction. As a result, the country is committed to sustainable reforms that strive to bolster the sector by enhancing food security, poverty reduction and significant improvement of household incomes. Despite all the efforts being implemented, the sector has hardly realized the set targets. This has to a great extent been linked to low awareness and use of improved agricultural technologies, limited scope for expanding farm lands, and poorly coordinated multi-sectoral approach to rural development (Ragasa et al., 2014). In this light, there is an urgent need to implement initiatives that aim at buttressing farmers in addressing their challenges to increase agricultural productivity. One of the major initiatives to achieve this is through provision of well-coordinated agricultural advisory services to small-scale farmers.

Agricultural extension services are among the essential impetus of change in Sub-Saharan Africa including Kenya with regard to reduction of poverty, increase in household income and promotion of household food security. However, despite the introduction of extension programmes since independence, the achievements in terms of rural income, food security and poverty reduction have been minimal. As a result, there has been a springboard in efforts to transform and bolster agricultural advisory systems to pluralistic agricultural extension programmes in line with the broader goals of improving rural livelihoods through increased agricultural productivity and farm income (Singh et al., 2016). This has considerably arisen due to the limited effectiveness of the existing agricultural extension models in the developing countries, Kenya included. A key challenge facing the existing pogrammes is the over-reliance on the top-down extension approach, that mostly sidelines the farmer in the decision-making process.

Since independence, extension systems have focused on strategies reflecting agricultural and rural development goals (Davis, 2008). A well-designed and implemented extension plan can tremendously increase agricultural productivity (Swanson \& Rajalahti, 2010). This is the backdrop of considering the future direction of extension in Kenya. Initially, extension services were supply driven and solely provided through the Ministry of 
Agriculture (MoA) in a top-down approach limiting farmers' participation (Gido et al., 2014). The introduction of Training and Visit ( $\mathrm{T}$ and $\mathrm{V}$ ) Extension model was a vital milestone in the history of extension services in Kenya. The premise of $\mathrm{T}$ and $\mathrm{V}$ was that there was enough technology awaiting diffusion and adoption by farmers (Anderson \& Feder, 2005). It was first introduced in Kenya on a pilot basis in 1982 and was useful in the adoption of hybrid seeds and fertilizer especially in the high-potential areas but had little effect on productivity and incomes among farmers in rain-fed areas.

In the mid-1990s, the GoK and World Bank started exploring new approaches to an extension system that would address these constraints (MoALF, 2015). In 2001, the MoA formulated National Agricultural Extension Policy (NAEP) to link research and extension activities, decentralize decision making and integrate public and private service providers to resolve issues facing farmers. To operationalize NAEP, MoA prepared National Agricultural and Livestock Extension Programme (NALEP) to enhance the contribution of agriculture to the country's economic growth (Ngigi et al., 2011). Furthermore, it was endeavoured to make extension demand driven and increase its efficiency in the country. Despite these efforts, there have been mixed results regarding the effectiveness of agricultural extension systems. In response, Egerton University in collaboration with other stakeholders piloted the Farm Attachment Programme (FAP) in Baringo and Nakuru counties to engage students to specific farms for at least eight weeks in cohorts. Direct attachment of students to farms facilitate the transfer of innovations and technologies that can improve farm performance and agricultural productivity resulting in socio-economic progress (Kalule et al., 2014).

Farm attachment is a work related form of learning that includes a period of learning in a farm setting (Edziwa et al., 2012). Students agriculture related disciplines are attached directly to farms to gain hands-on experience. Attachment in Egerton University for practical exposure takes 8-10 weeks scheduled for third year Bachelor's degree students and second year diploma students. The primary role of farm attachment is to provide exposure to the real world of work (Mungai et al., 2016). During this programmeme, students put into practice the technical skills and theory learned in their curricula.

Educators and policy makers have called for models of learning and teaching that would change the role of instructors from knowledge deliverers to facilitators of proactive student learning. Agricultural discipline should therefore, reflect on foundational principles of learning by analyzing emerging issues rather than concentrating on foundational principles of the discipline. Masimira (2012) argues that experiential learning has a connection to real life issues faced by students outside the classroom both present and in the future. Experiential learning promotes students' problem-solving abilities, critical thinking, synthesizing academic knowledge and applying technical skills in real life situations.

Premised on the current status of extension in Kenya and Sub-Saharan Africa, there has been profound motivation to experiment wide-ranging alternative methods with greater emphasis on pluralistic farmer-led extension services (Lyne et al., 2017). Due to the diversity of approaches mirroring the heterogeneity of rural areas, extension agents will need special skills that go beyond the basic technical skills. Based on the current status of extension in Kenya, there is a dearth literature on the capacity and performance of extension system. This type of information is needed to assess the SWOT of extension to buttress efforts of reducing rural poverty through the improvement of small-scale farmers' welfare (Sæther, 2010).

\subsection{Methodology \\ 2.1 Study Area}

The study was conducted in Baringo and Nakuru counties in the rift valley region of Kenya. Nakuru County County covers an area of $7495.1 \mathrm{~km}^{2}$. It lies between Longitude $36^{\circ} 00^{\prime} 0.00^{\prime \prime}$ E and latitude $0^{\circ} 29^{\prime} 59.99^{\prime \prime} \mathrm{N}$. It's the fourth largest county in Kenya in terms of population with a population of 1,603,325 from the 2009 census survey (Nakuru County Integrated Development Plan, 2013). Main crops grown and marketed include coffee, maize, wheat, barley, and beans. Major industries in the County are flour milling and grain ginneries with crops from the county providing the primary source of raw materials.

Nakuru County experiences a bimodal rainfall pattern with highs of $1800 \mathrm{~mm}$ and lows of 500mm (Nakuru County Integrated Development Plan, 2013). There are about 400,000 households, 25\% of which are femaleheaded. Rich volcanic soils, energetic labour force, reliable rainfall in most parts of the County and availability of ready market have contributed to an increase in cultivated land. Approximately, $72.5 \%$ of lands in the county have title deeds with less than $20 \%$ of the households considered landless. Land under food crops in the county is $243,711.06$ hectares while $71,416.35$ hectares is under cash crops (Nakuru County Integrated Development Plan, 2013). The average farm size for both food and cash crops per household is 0.77 hectares. Dairy farming under zero grazing system is on the rise as a vital economic activity due to the favourable weather environment, diminishing land size and ready market for milk.

Baringo County has a population of 555,561 (279,081 males and 276,480 females) in the 2009 Kenyan census. The county lies between Longitude $36^{\circ} 00^{\prime} 0.00^{\prime \prime} \mathrm{E}$ and Latitude $0^{\circ} 39^{\prime} 59.99^{\prime \prime} \mathrm{N}$ (Baringo County Integrated Development Plan, 2013). The county's inter-censual growth rate is at $3.3 \%$ per annum, which is 
above the national average of 3\%. Baringo County is in the Great Rift Valley region of Kenya and covers an area of $11,015.3 \mathrm{~km}^{2}$. Baringo County varies in altitude with the highest points being $3000 \mathrm{~m}$ above the mean sea level and low points being nearly $700 \mathrm{~m}$ above the mean sea level. Baringo is classified as an ASAL. Rainfall varies between $1000 \mathrm{~mm}$ and $1500 \mathrm{~mm}$ in the highlands to $600 \mathrm{~mm}$ per annum in the lowlands (Baringo County Integrated Development Plan, 2013). Koibatek Sub-County receives the highest rainfall amount while the lowland sub-counties of Mogotio, Baringo North, and East Pokot receive relatively low amounts. Temperature ranges from $10^{\circ} \mathrm{C}$ to $35^{\circ} \mathrm{C}$ with an average wind speed of $2 \mathrm{~m} / \mathrm{s}$ with the climate varying from humid highlands to arid lowlands. The major crops grown in the area include Maize, sorghum, finger millet, beans, cowpeas, garden peas, green grams, sweet potatoes and Irish potatoes. Beans and maize cover the largest acreage while garden peas cover the lowest acreage (Baringo County Integrated Development Plan, 2013). Maize is the leading cash and food crop in the county although its production has been low due to poor crop husbandry and poor rainfall distribution.

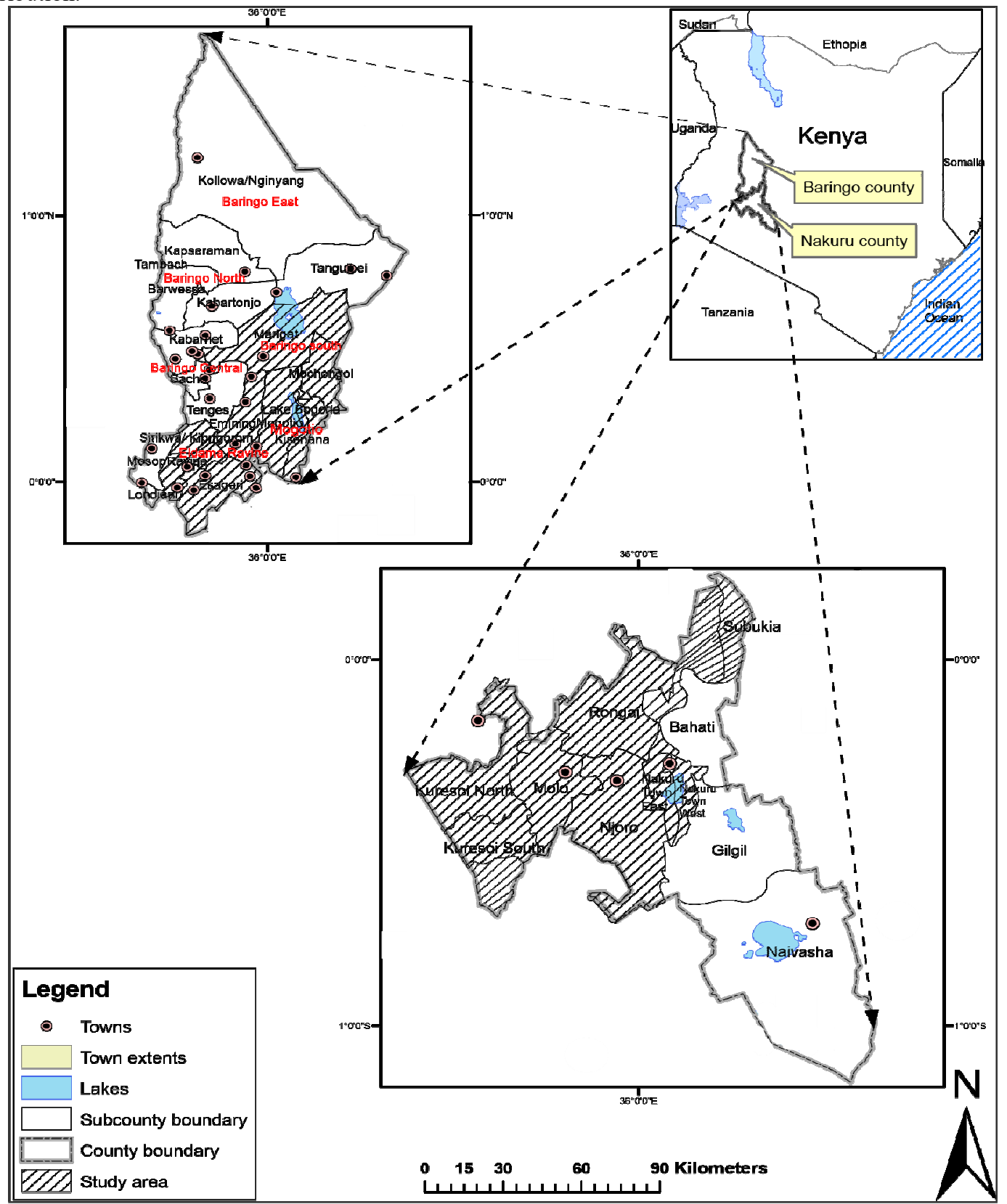

Figure 1: Map of Baringo and Nakuru Counties in Kenya

Source: World Resource Center (2016) 


\subsection{Research design and data management}

A household survey was conducted in Baringo and Nakuru Counties on all the farmers that had been engaged in the programme since its inception in 2014. The Counties were purposively sampled because the programme was piloted here. Data was collected by trained enumerators using semi-structured questionnaires through interview schedules and observations. A total of 100 farmers were interviewed, with 68 from Nakuru and 32 from Baringo County.

\subsection{Analytical framework}

To determine the strengths, weaknesses, opportunities and threats (SWOT) of the FAP, farmers' perceptions towards the programmeme were condensed into four composite clusters. To determine the SWOT analysis of the programmeme, 27 variables were subjected to factor analysis through principal component factoring. The constructs were then rotated using an Oblique rotation technique due to suspected inter-correlations between the constructs as represented in equation 3. Reliability and internal consistency tests were then conducted to ensure that the model was suitable for the data. Afterwards, the observed and the latent variables were combined to come up with clusters that were renamed as strengths, weaknesses, opportunities and threats based on factor loadings (Olivier et al., 2018).

$Y_{1}=q_{11} x_{12}+q_{12} x_{2}+\ldots \ldots \ldots+q_{1 n} x n$

$Y_{j}=q_{j 1} x_{j 1}+q_{j 2} x_{2}+\ldots \ldots \ldots+q_{j n} x_{n}$

Where $Y_{1}, \ldots \ldots \ldots \ldots \ldots \ldots \ldots \ldots Y_{j}=$ Correlated factor constructs

$q_{1}-q_{n}=$ Correlation coefficients

$x_{1}-x_{j}=$ Farmer perceptions towards the programmeme.

\section{Pre-diagnostic tests for the confirmatory factor analysis}

A CFA model was employed on standardized variables to condense the number of interrelated variables into few factors that were grouped into strengths, weaknesses, opportunities and threats (Teryima, 2016). Since the variables under analysis were conceived multidimensional, various dimensions were non-orthogonal resulting into relatively high correlations. Therefore, to fully capture the diversity in the human behaviour by condensing these variables into fewer components for easier rotation, a Promax rotation was employed (Brown, 2009). This rotation created factor loadings ranging from 0.30 to 0.830 , clustering the items into four extracted factors.

Prior to the extraction of factors, several pre-estimation tests were conducted to assess the suitability of the data and adequacy of the sample size for factor analysis. The data was screened for out-of-range values and univariate outliers by observing the factor loadings on each of the factors that were analyzed for the model. As a result, variables that had factor loadings of less than 0.30 were according to Olivier et al. (2018) identified and dropped, a test that strengthened the Cronbach's alpha. Excluding the loadings that were less than 0.30 yielded a sixteen-factor solution from 27 factors. Premised on literature contention regarding the appropriate or minimum sample size for factor analysis to be effective, the data was satisfactory for factor analysis as a sample size of at least 100 has been suggested sufficient (Thompson, 2004; Brown, 2009; Teryima, 2016; Olivier et al., 2018). Furthermore, the data was sufficient for the execution of a CFA model as it provided a ratio of over 6 cases per variable with a sampling ratio of 6.25 (Glen, 2017). To enhance the model further, missing data was subjected to listwise deletion.

Regarding the number of component extraction, the model has for quite some time been acutely criticized for subjectivity (Thompson, 2004; Tsai \& Liou, 2017). To overcome the criticisms, the latent variables were subjected to a series of systematic and sequential pre-estimation tests prior to factor construction and reduction to establish a clear decision pathway regarding the strengths, weaknesses and opportunities extraction. A series of decisions were therefore, made before coming to a four-item factor structure. This was after reviewing the Eigen values, factor loadings, scree plot, and reliability and validity statistics (Thompson, 2004; Brown, 2009; Glen, 2017; Hauben et al., 2017; Teryima et al., 2016).

Cronbach's alpha for reliability, Kaiser-Meyer-Olkin (KMO) measure of sampling adequacy and Bartlett's test of Sphericity were conducted prior to the factor analysis to determine if factor analysis was a suitable model for this data. The pre-estimation tests proofed that factor analysis was a suitable model, yielding a Kaiser-MeyerOlkin (KMO) measure of sampling adequacy of 0.619 with an associated $p$ value of $<0.001$. This indicated that the sampling was adequate for factor analysis as a $\mathrm{KMO}$ of 0.6 has been suggested to be suitable, thereby indicating that partial correlation was minimal (Glen, 2017; Olivier et al., 2018). Furthermore, a Cronbach's alpha of 0.705 was obtained. According to Teryima et al. (2016), the Cronbach alpha should at least be 0.7. A Cronbach's alpha of 0.705 , indicated that $70.5 \%$ of the of the 27 variables that were used in determining the SWOT of the programme were consistent. According to Olivier et al. (2018); Tsai \& Liou (2017), this indicated 
a good internal consistency and reliability, further indicating that factor analysis was a suitable model for this data.

Despite the fact that majority of the communalities obtained were higher than 0.6, only one variable had a communality value above 0.8 . This indicated a weak association between the variables used in the model (Hauben et al., 2017). The analysis yielded a KMO and Bartlett's test of Sphericity value of 0.619 with an associated p-value of 0.000 indicating that the set of variables derived were adequately related, therefore, validating the use of factor analysis model and Promax rotation (Brown, 2009; Glen, 2017; Olivier et al., 2018). The confirmatory factor analysis model results are presented in Table 1.

\subsection{Results and discussion}

To determine the strengths, weaknesses, opportunities and threats of the FAP, Confirmatory Factor Analysis (CFA) model was used. Students from different departments in agriculture and education discipline were attached to farmers with different resources, education level, farming experience and social capital among other factors as advisory agents. With the farmers' identification of the programmes' SWOTs being subjective, errors were likely to occur during categorization. Therefore, to avoid misspecification errors, the study employed a CFA model to ensure correct categorization of the individual factors into strengths, weaknesses, opportunities and threats as experienced by farmers in the FAP (Glen, 2017).

Table 1: Confirmatory factor analysis model results

\begin{tabular}{|c|c|c|c|c|c|c|}
\hline \multicolumn{2}{|l|}{ Constructs } & Factor1 & $\begin{array}{r}\text { Facto } \\
\mathbf{r 2} \\
\end{array}$ & $\begin{array}{r}\text { Facto } \\
\text { r3 }\end{array}$ & $\begin{array}{r}\text { Facto } \\
\text { r4 } \\
\end{array}$ & $\begin{array}{r}\text { Communali } \\
\text { ties }\end{array}$ \\
\hline \multicolumn{2}{|l|}{ Timely Feedback by the students } & 0.632 & -0.199 & 0.008 & -0.294 & 0.580 \\
\hline \multicolumn{2}{|l|}{ Increase in farm yields } & 0.635 & 0.151 & -0.010 & 0.232 & 0.665 \\
\hline \multicolumn{2}{|l|}{ Increase in food security } & 0.686 & 0.100 & -0.020 & 0.001 & 0.673 \\
\hline \multicolumn{2}{|c|}{ Higher responsiveness by students to farm challenges } & 0.679 & -0.083 & 0.136 & -0.051 & 0.682 \\
\hline \multicolumn{2}{|l|}{ Increased technology awareness } & -0.126 & 0.645 & 0.150 & 0.071 & 0.765 \\
\hline \multicolumn{2}{|l|}{ Increased technology access } & 0.035 & 0.763 & -0.056 & -0.031 & 0.645 \\
\hline \multicolumn{2}{|l|}{ Increase in farm efficiency } & 0.419 & 0.447 & -0.009 & -0.100 & 0.557 \\
\hline \multicolumn{2}{|l|}{ Increased farmer Linkage } & 0.317 & 0.326 & 0.013 & -0.024 & 0.716 \\
\hline \multicolumn{2}{|l|}{ Enterprise incompatibility } & 0.346 & 0.441 & -0.116 & 0.150 & 0.644 \\
\hline \multicolumn{2}{|l|}{ Mismatch of student skills } & 0.154 & -0.092 & 0.312 & -0.036 & 0.803 \\
\hline \multicolumn{2}{|l|}{ Drastic climate variability and drought } & 0.037 & -0.036 & 0.830 & 0.044 & 0.711 \\
\hline \multicolumn{2}{|c|}{$\begin{array}{l}\text { Limited resources by farmers to implement the } \\
\text { interventions }\end{array}$} & 0.053 & 0.111 & 0.828 & -0.089 & 0.729 \\
\hline \multicolumn{2}{|c|}{ Interpersonal relationship challenges } & 0.022 & 0.207 & 0.336 & -0.276 & 0.688 \\
\hline \multicolumn{2}{|l|}{ The attachment duration was short } & -0.190 & 0.187 & -0.205 & 0.760 & 0.734 \\
\hline \multicolumn{2}{|l|}{ High costs of student accommodation } & 0.009 & 0.024 & -0.472 & -0.671 & 0.753 \\
\hline \multicolumn{2}{|l|}{ Culture differences } & 0.224 & -0.508 & -0.144 & $\mathbf{0 . 5 3 0}$ & 0.772 \\
\hline \multicolumn{2}{|l|}{ Eigen values } & 2.958 & 2.08 & 1.648 & 1.448 & \\
\hline \multicolumn{2}{|l|}{ Cumulative percentage } & 15.567 & $\begin{array}{r}35.19 \\
2 \\
\end{array}$ & $\begin{array}{r}49.61 \\
6 \\
\end{array}$ & 61.72 & \\
\hline \multicolumn{7}{|l|}{ Kaiser-Meyer-Olkin Measure of Sampling } \\
\hline Bartlett's Test of Sphericity & $\begin{array}{l}\text { Approximate } \\
\text { Square } \\
\text { Degrees of fr } \\
\text { Significance }\end{array}$ & $\begin{array}{l}\text { Chi- } \\
\text { edom }\end{array}$ & $\begin{array}{r}0.0 \\
0 . \\
\end{array}$ & $\begin{array}{r}34 \\
36 \\
05 \\
\end{array}$ & & \\
\hline
\end{tabular}

Extraction Method: Principal Axis Analysis.

Rotation Method: Promax with Kaiser Normalization.

In total, 27 variables relating to SWOTs of the FAP were included in the factor analysis with Promax (Oblimin) rotation. The analysis yielded four factors explaining $61.72 \%$ of the variance of the entire set of variables. Factor 1 was labelled Strength (S), due to higher loadings by the following items; timely feedback by students, increase in farm yields, increase in food security and higher responsiveness by students. This factor explained $15.56 \%$ of the variance. The second factor derived was labelled Opportunity $(\mathrm{O})$. This was due to the correlation of the following variables; increased technology awareness, increased technology access, increase in farm efficiency and increased farmer linkages. This factor explained $19.63 \%$ of the variance.

The third factor was labelled Weaknesses (W) after the following variables loaded robustly; interpersonal challenges, Mismatch of student skills to the farmers' needs and expectations, and at times timing of the farm attachment could be unfavourable (drastic climate variability and drought). Weaknesses explained $14.42 \%$ of the 
variance. Lastly, the fourth factor was labelled as Threats $(\mathrm{T})$ as the highest loadings included: short attachment duration, high costs of student accommodation, and cultural differences. The variance explained by this factor was $12.10 \%$.

Table 2: The SWOT Matrix of the programme

\begin{tabular}{|c|c|}
\hline $\begin{array}{l}\text { Strengths } \\
\text { - Timely feedback by students to farmers } \\
\text { - Increased farmer linkages } \\
\text { - Food security (diversification of food crop } \\
\text { production) } \\
\text { - Higher responsiveness by students }\end{array}$ & $\begin{array}{l}\text { Weaknesses } \\
\text { - Interpersonal challenges } \\
\text { - Mismatch of student skills } \\
\text { - Short attachment duration }\end{array}$ \\
\hline $\begin{array}{l}\text { Opportunities } \\
\text { - Increased technology awareness } \\
\text { - Increased technology access } \\
\text { - Farm efficiency } \\
\text { - Increase in farm yields }\end{array}$ & $\begin{array}{l}\text { Threats } \\
\text { - Unfavourable timing of the farm } \\
\text { attachment (Drastic climate variability and } \\
\text { drought) } \\
\text { - High costs of student accommodation } \\
\text { - Cultural differences }\end{array}$ \\
\hline
\end{tabular}

\subsection{Strengths}

\subsubsection{Timely Feedback by students}

Nearly half, $48 \%$ of the farmers in the programme felt that the students gave prompt response and solutions regarding the challenges that arose. The traditional top-down extension services as asserted by Nambiro et al. (2006), extension agents would assess farmers' situations in time but take relatively longer before responding back to the farmers. On the other hand, students worked hand in hand with farmers to give them real-time solutions and suggestions for implementations. This arrangement, therefore, makes it easier to monitor the proposed recommendations after which if not effective, the necessary adjustments are effected before farmers committing substantial resources.

\subsubsection{Increase in farm yields}

Notably, majority of the farming households in Sub-Saharan Africa are smallholder, profoundly affected by climatic and non-climatic shocks, traditional farming techniques, and policy inconsistencies (Muyanga \& Jayne, 2006). As a consequence, farmers in the region have been trapped under low agricultural productivity circle. the programme was designed to address the challenge of low productivity through the introduction of appropriate technological solutions.

Approximately $60 \%$ of the farmers in the programme perceived that they had largely benefitted from the direct interaction with students in terms of farm output relative to the previous years. They said that this arrangement gave them an opportunity to experience both the practical and theoretical knowledge gained by students in their curriculum. Through this interaction, farmers were introduced to science and technology such as soil testing, improved seed variety, improved breeds and improved agricultural techniques.

Consequently, students from the institution are technically equipped and imparted with these techniques and information, thereby transferring the same to the farmers. Farmers attributed the significant increase in their farm yields to the new techniques and practices introduced by the students. In a similar arrangement undertaken by extension agents, Lyne et al. (2017), echoes similar sentiments that extension agents transfer the knowledge and techniques gained through specialized agricultural related training, conferences and seminars attended. Similarly, Hamilton and Hudson (2017) found that agricultural extension and advisory services have positive impacts on farm output and earnings.

Increase in farm yields could allude that new technologies ensures that farmers utilize their resources efficiently optimizing their yields. Furthermore, farmers predicted that their output will remain high as the students engaged them in all the phases of the technical implementation. According to Lavison (2013), when farmers articulately understand the specific operations to undertake to curb production inefficiencies in their farm, they become more innovative in curbing occasional farm challenges.

\subsubsection{Food security}

Approximately $27.7 \%$ of the Kenyan population according to FAO et al. (2015) is worryingly undernourished. After explaining to the farmers what food security entails (state of having reliable access to a sufficient quantity of nutritious food), $21 \%$ of the farmers indicated that the programme had significantly made them food secure. The farmers attributed this status to the new agricultural technologies and practices like diversification of agricultural enterprises introduced by students on attachment. This ensured that farmers had a variety of agricultural products, which were not only economically beneficial but also met their dietary needs and food 
preferences. More than half of the farmers, $54 \%$ confirmed that in as much as they produced to maximize output and therefore profit, they diversified the farm production capacities to meet their dietary needs.

\subsubsection{Higher responsiveness by students}

About $57 \%$ of the farmers in the programme observed that students responded promptly to the challenges that arose on the farm by giving real-time solutions. The timely reaction saved them from incurring heavy losses and expenses as problems on the farm were dealt with in their earlier stages. This was possible since the students were available on the farm throughout the entire attachment period. An aspect that made the farmers rank this arrangement higher than the extension services provided by the ministry of agriculture (Terblanché, 2008). This could be attributed to the fact that the students worked hand-in-hand with farmers ensuring that the farmers understood when and how they should react to farm issues. Furthermore, the farmers also reaffirmed that the programme availed unprecedented opportunities in form of technological solutions to overcome the time-to-time challenges experienced on their farms (Ragasa, 2014).

\subsection{Weaknesses}

\subsubsection{Mismatch of students' skills to farmers' expectations and needs}

Farmers had high expectations from the programme, and therefore, the students. This did not dawn well on a section of farmers as $13 \%$ were dissatisfied with the technical skills and advisory capabilities of students. This could be attributed to the enterprise specificity among some of the farmers in the programme.

Majority of the farmers who were dissatisfied with the students' abilities, $77.54 \%$ undertook only one agricultural enterprise, either livestock farming or horticulture. For instance, if a student from the department of crops, horticulture and soils is taken to a farmer specializing only in livestock activities, there is a higher likelihood of such a student struggling to meet the expectations of such a farmer. A similar scenario is possible when a student from the department of animal science and veterinary science is attached to a farmer who has specialized in crops. However, this challenge can easily be addressed by succinctly reviewing the enterprises undertaken by different farmers before attaching students. Additionally, the curriculum can be reviewed to entail practical learning to fully equip students with technical farm knowledge.

\subsubsection{Interpersonal challenges}

In terms of interpersonal relationship with the students, $16 \%$ of the farmers indicated that they experienced interpersonal challenges with students. This ranged from communication challenges, staple food, tradition, beliefs and gender. This could be explained by the conventional admission of students from different parts of the country with different ethnical backgrounds diverse cultural and traditional beliefs by the University. As a result, differences in the local languages between the farmers and students could result though not to a large extent, to communication barrier.

Diverse cultures and traditions could mean that the types of cuisines in the places of attachment could not be what the students are used to, making it hard for them to adjust. This made a number of farmers to propose that students brought for attachment should look for places of residence during the attachment periods and only avail during the day for farm work responsibilities. Furthermore, some farmers indicated that there were abrasions between the students and the workers on the farm with some workers feeling that they were more conversant with farm challenges and therefore, operations as compared to the students. Hence, making it hard to implement some of the interventions brought by the students.

A number of farmers especially those in cooperatives and SACCOs claimed that there were instances of abrasions between employees and the students. They attributed the abrasions to the potential threat that students posed to their position due to inferior qualifications relative to the students. As a result, there were instances of reluctance among the full-time employees in disclosing pertinent information to the students. A similar experience was reported in a study conducted on Distance Learning (ODL) in Zimbabwe by Bukaliya (2012), where abrasions between fulltime employees and interns militated the effectiveness of the internship programme besides employers treating interns as sources of cheap labour and temporary solutions for shortfalls in the industrial labourers.

\subsubsection{Unfavourable timing (Attachment during off-season)}

A section of the farmers (15\%), observed that the periods during which they received students, the weather was unfavourable making it hard to undertake most of the interventions proposed by students, particularly agronomic practices, as they were weather-dependent. Most of the farm activities or enterprises undertaken by farmers in Nakuru and Baringo counties are weather depended. The primal activities undertaken by the farming households in the programme are agronomy and dairy farming. Majority of these farmers indicated that they received students mostly in September and January when the climate was not favourable, particularly for farmers who were not practising irrigation to benefit from the technological solutions and interventions introduced by students. Consequently, this minimized the overall benefits that farmers could have instead accrued from the interaction making the FAP not as effective as it could have otherwise been. This conformed to the assertions by Kibett (2011), who reported that agricultural activities in Sub-Saharan Africa are undermined by adverse 
climatic and weather shocks.

\subsection{Opportunities}

\subsubsection{Increased technology awareness and access}

Since students had been exposed to new and improved production techniques through their class and practical sessions at the university, $67 \%$ of the farmers in the programme indicated that students had introduced them to new agricultural technologies and practices. Farmers expressed their satisfaction with the programme's commitment to the free flow of agricultural information, training and retraining programmes through students on attachment. Majority of the farmers in the programme agreed that students' interventions and solutions enhanced their innovative capacity regarding their production activities. This conformed to the assertions of Lavison (2013); Mwangi \& Kariuki (2015) who claimed that technology enables farmers to transform their routine traditional practices through enhanced innovative capacity.

Majority of the farmers, $70 \%$ claimed to have been introduced to; new animatics, new agronomic practices, crop rotation, intercropping, relay cropping, tillage management, chemical innovations, strip growing, improved seeds, soil and water conservation, artificial insemination, silage management, new pests and disease control, new crop varieties and livestock breeds, green house farming and value addition. Majority of these farmers felt that the programme had presented them with the opportunity to access technologies that they had not been initially exposed to or used but failed due to inadequate knowledge and technological know-how of efficiently articulating them.

\subsubsection{Increase in farm efficiency}

Majority of farmers in the programme indicated that their mentality towards farming had been changed after their interaction with students. Approximately $51 \%$ of the farmers felt that students had compelled them to treat their farms as systems that needed to be evaluated regularly and upgraded in terms of new agricultural practices, including recording keeping. They pointed out that they had been introduced to new practices that not only minimized agricultural costs of production but also increased output and revenue per unit of inputs invested. This made them perceive farming as a self-sustaining and profitable enterprise.

Moreover, the farmers indicated that the programme was effective in assisting them to reduce the cost of labour incurred in the day-to-day farm operations. The students assisted in farm evaluation and planning, making majority of farmers in the programme to realize that cutting on the number of workers on the farm and contracting them on a daily basis was more economical and effective, saving them significant amounts of money that they channeled in other activities on the farm. Farmers attributed the efficiency on their farms to their mutual participation in the programme as they were able to learn and be incorporated in every stage of intervention at the farm level. As a result, farmers learned more from the students. This could translate into a more sustainable and long-lasting changes both at the farm level and in the overall behaviour of the farmers (Wandji et al., 2012).

\subsubsection{Increased farmer linkage}

Not all farmers from the two counties received students. Therefore, they shared the students particularly those in groups and in co-operative societies with students moving from the host farmers to other farmers to also assist them. Majority of the farmers attested that initially, they could hardly access their neighbours' farms and exchange ideas on agricultural matters as many feared for duplication of their farming strategies and ideas. However, with the dawn of the programme, students were could reach out to a number of farmers in the same vicinity. As a result, farmers started interacting and visiting each other's farms to see what the students had done, particularly those that were not in the programme.

As a result, a number of farmers started sharing ideas and experiences, a move they indicated had jointly improved their farming practices. Furthermore, this interaction according to farmers increased their urge to link up with other agricultural stakeholders particularly credit providers, input providers, the ministry of agriculture, extension agents, agricultural co-operatives and other marketing agencies. This outcome as asserted by farmers enhanced their agricultural production throughout the chain as it fostered linkages between farmers and other pertinent agricultural stakeholders.

\subsection{Threats}

\subsubsection{Insufficient attachment duration}

Approximately $66 \%$ of the farmers in the programme reported that the period allocated for attachment ( 8 weeks) was too short citing that it elapsed before majority of the specific projects that had been initiated by students came to completion. As a consequence, farmers were at risk incurring losses especially if left without guidance for the remaining phases of the projects introduced. This compelled a number of farmers not commit their resources with fears of failure due to the project initiators and implementers leaving early. Besides, farmers indicated that trainings introduced by the students were very beneficial although, short-lived. This was a problem particularly to the farmers who were members of co-operative societies and groups as they reported to have shared a student(s) therefore, increasing the demand for the programme in the two counties. Bukaliya (2012) 
emphasized that the duration that has been allocated for attachment in different disciplines is insufficient both for the students and their potential employers.

\subsubsection{High costs of student accommodation}

About $46 \%$ of the farmers felt that hosting a student(s) was expensive. Since majority of the farmers resided far from the university, they had to host them on their farms. The farmers posited that since these students were instrumental in technological interventions and solutions on their farms, they were independently and personally obliged to support them during their stay on the farms. The support according to the farmers and students was in terms of food, shelter, fare, stipend and at times talk time among other necessities. Some farmers pointed out that they had to give the students special treatment to maintain a healthy and positive relationship with the university in addition to the great assistance these students were offering on their farms. As an effect, some farmers suggested that the University should provide accommodation and financial assistance to the students to relieve them off some burden during the attachment period.

\subsubsection{Cultural differences}

With the University admitting students from all walks of life, $30 \%$ of the farmers found cultural diversity a challenge since farmers do not have the sole option of choosing the student(s) to be attached to them based on religion, gender and place of origin among other factors. Cultural diversity according to farmers was both a positive and negative challenge or experience. On one side, it provided the opportunity to learn and appreciate other peoples' culture and tradition (way of doing things and beliefs) particularly those that seemed friendly and appealing. Diametrically, some of the farmers indicated that other cultures put on show by some students were unappealing, making it hard to accommodate such students.

\subsection{Conclusions and Policy implications}

The response of students to farm challenges was important in determining how the farmers perceived the impact of FAP on their farming activities and agricultural productivity in general. The programme increased technology awareness and access among farmers. In addition, majority of the farmers believed that the programme was likely to increase farmer linkages within the Counties. Furthermore, high cost of student accommodation was a threat to the sustainability of programme. However, the programme was limited by short attachment duration. Each attachment cohort was designed to take 8 weeks which majority of the farmers indicated was insufficient for implementation of some interventions. Attachment duration should be reviewed to at least twelve or more weeks to ensure successful implementation of the interventions introduced by the students. The programme implementers should incorporate extension agents in the FAP to ensure the students on attachment and the extension agents complement each other and ensure effective integration of the theory learned in a classroom set-up by the students to real-farm situations. This would enhance the students' hands-on experience and equip them with the necessary technical skills. Based on the strengths and opportunities presented by the FAP, the programme should be expanded to other counties. Furthermore, the national government in collaboration with the county governments should implement land land reforms to facilitate farmers' acquisition of title deeds with ease. This would motivate farmers to undertake long-term investments and technologies due to reduced uncertainty associated with insecure land tenure systems. Furthermore, this will cushion farmers as collateral in the acquisition of agricultural credit from financial institutions, as a result, motivate them to adopt improved farming techniques.

\section{Acknowledgment}

The authors would like to sincerely thank the Regional Universities Forum for Capacity Building in Agriculture (RUFORUM) who provided funding for this research through RU 2014 NG 12 Project. We would also like to who thank the farmers in the Farm Attachment Programme and the Egerton University students who decided to be attached in the farm attachment programme. The efforts and contributions of Egerton University, particularly through the department of field and industrial attachment personnel cannot go unnoticed.

\section{References}

Anderson, J. R. \& Feder, G. (2005). Agricultural Extension: Good Intentions and Hard Realities. The World Bank Research Observer 19(1): 41-60.

Baringo County Integrated Development Plan. (2013). The External Dataset 2013-2017. Baringo County Integrated Development Plan.

Brown, D. J. (2009). Choosing the Right Type of Rotation in PCA and EFA, Statistics Corner. JALT Testing and Evaluation SIG Newsletter, 13 (3): 20-25.

Bukaliya, R. (2012). The potential benefits and challenges of internship programmemes in an ODL institution: A case for the Zimbabwe Open University. International journal on new trends in education and their implications, 3(1): 118-133.

Davis, K. (2008) Extension in Sub-Saharan Africa: Overview and Assessment of Past and Current Models and 
Future Prospects. Journal of International Agricultural and Extension Education, 15(3): 15-28.

Edziwa, X., Chakamba, N., Cryton, J. and Chiweshe, M. (2012). Experiential Learning in Agriculture Education: A Zimbabwean Experience. International Journal of Humanities and Social Science, 2(21): 280-285.

FAO, IMF, \& UNCTAD. (2015). Price Volatility in Food and Agricultural Markets: Policy Responses. Rome, FAO.

Gido, E. O, Ayuya, O. I, Sibiko, K.W. \& Mwangi, J.K. (2014). Demand for Agricultural Extension Services Among Small-Scale Maize Farmers: Micro-Level Evidence from Kenya. Journal of Agricultural Education and Extension, 1: 1-14.

Glen, S. (2017). Kaiser-Meyer-Olkin (KMO) Statistics how to Test for Sampling Adequacy. http://www.statisticshowto.com/kaiser-meyer-olkin/ Accessed on $24^{\text {th }}$ May, 2018

Hamilton, A. \& J. Hudson. (2017). "The Perceived Impact of Agricultural Advice in Ethiopia." The Journal of Agricultural Education and Extension, 23(2): 159-173. doi:10.1080/1389224X.2016.1245151/ 29 $9^{\text {th }}$ January, 2018

Hauben, M., Hung, E. \& Hsieh, W. Y. (2017). An exploratory factor analysis of the spontaneous reporting of severe cutaneous adverse reactions. Therapeutic Advances in Drug Safety, 8(1): 4-16. http://doi.org/10.1177/2042098616670799/ $14^{\text {th }}$ March, 2018

Kalule, S. W., Mugonola, B., Odongo, W. \& Ongeng, D. (2014). University Student-Centered Outreach for Rural Innovations and Community Transformation in Northern Uganda. Fourth RUFORUM Biennial Regional Conference 21 - 25 July 2014, Maputo, Mozambique: 635- 647.

Kenya National Bureau of Statistics (KNBS). (2018). Economic Survey 2017. Central Bureau of Statistics, Ministry of Finance and Planning. Nairobi, Kenya.

Kibett, C. (2011). Major Challenges facing Kenyan agricultural sector. International

Knobloch, N. A. (2003). Is Experiential Learning Authentic? University of Illinois. Journal of Agricultural Education, 44(4): 22-34.

Lavison, R. (2013). Factors Influencing the Adoption of Organic Fertilizers in Vegetable Production in Accra, M.Sc. Thesis, Accra Ghana.

Lyne, M., Jonas, N. \& Ortmann, G. (2017). A quantitative assessment of an outsourced agricultural extension service in the Umzimkhulu District of KwaZulu-Natal, South Africa. Journal of Agricultural Education and Extension 4 (1): 1-15.

Masimira, F. (2012). Report on Ministry of Higher and Tertiary Education: Consultative meeting on industrial attachment for university students. $21^{\text {st }}$ February 2012 Management Training Bureau.

Ministry of Agriculture Livestock and Fisheries (MoALF). (2015). Agricultural Sector Development Support Programmeme, ASDSP Annual Work plan and Budget, Nairobi.

Muyanga, M. \& T. S. Jayne. (2006). Agricultural Extension in Kenya: Practice and Policy Lessons. Tegemeo Institute of Agricultural Policy and Development. Working Paper 26, Egerton University, Nairobi, Kenya.

Mwangi, M. and Kariuki, S. (2015). Factors Determining Technology Adoption of New Agricultural Technology by Smallholder Farmers in Developing Countries. Journal of Economics and Sustainable Development, 6(5): 208-216.

Nakuru County Integrated Development Plan. (2013). The External Dataset, 2013-2017 Nakuru County Integrated Development Plan.

Nambiro, E., Omiti, J. \& Mugunieri, L. (2006). Decentralization and Access to Agricultural Extension Services in Kenya. Contributed Poster Prepared for Presentation at the International Association of Agricultural Economists Conference, Gold Coast, Australia, August 2006: 12-18.

Ngigi, M. W., Nkurumwa, A. O., Mbugua, S., Bebe, B. O., Mungai, N. W. \& Muliro P. (2011). NALEP II Impact Assessment Report. A report submitted to NALEP Coordinating Unit (NCU), Kilimo House, Nairobi, Kenya.

Olivier, S., De Montjoye, L., Tromme, I. \& Baeck, M. (2018). Two cases of annular acute generalized exanthematous pustulosis induced by terbinafine. European Journal of Dermatology, 1(1): 21-23.

Ragasa, C., Ulimwengu, J., Josee, R. \& Badibanga, T. (2016). Factors Affecting Performance of Agricultural Extension: Evidence from Democratic Republic of Congo. Journal of Agricultural Education and Extension, 22(2):113-143.

Sæther, B. (2010). Agricultural Extension Services and Rural Innovation in Inner Scandinavia. Norsk Geografisk Tidsskrift Norwegian Journal of Geography, 64(1): 1-9.

Singh, C., Dorward, P., \& Osbahr, H. (2016). Developing a holistic approach to the analysis of farmer decisionmaking: Implications for adaptation policy and practice in developing countries. Land Use Policy, 59, 329343.

Swanson, B. \& Rajalahti, R. (2010). Strengthening Agricultural Extension and Advisory Systems: Procedures for Assessing, Transforming, and Evaluating Extension Systems. ARD Discussion Paper 20. Washington, DC: World Bank. 
Terblanché, S. E. (2008). Towards an Improved Agricultural Extension Service as a Key Role Player in the Settlement of New Farmers in South Africa. Journal of Agricultural Extension, 37: 58-84.

Teryima, S. J., Fabrm, M., John, E. \& Philip, D. (2016). The Application of Total Quality Management (TQM) Approaches and Tools in Enhancing Goal Attainment in the Nigerian Brewery Manufacturing Firms: A Survey of Selected Brewery Manufacturing Firms in Nigeria.

Thompson, B. (2004). Exploratory and Confirmatory Factor Analysis: Understanding Concepts and Applications. Washington, DC, American Psychological Association.

Tsai, C. L. and Liou, Y. W. (2017). Determinants of work performance of seafarers. Maritime Business Review, 2(1): 36-51.

Wandji, D. N., Pouomogne, V., Binam, J. N. and Nouaga, R. Y. (2012). Farmer's Perception and Adoption of New Aquaculture Technologies in the Western Highlands of Cameroon. Tropicultura, 30(3): 180-184. 